\title{
CLINICAL MEASUREMENT OF THE ELECTRICAL RESISTANCE OF A PATIENT WITH AN AMPLIFIER TYPE OF ELECTRO- CARDIOGRAPH
}

\author{
BY \\ PIERRE JEANNERET \\ From the Sandoz Hospital (Dr. A. Delachaux), Lausanne, Switzerland \\ Received December 9, 1949
}

The electrical resistance of the patient plays an important part in the procedures for recording the various unipolar limb leads. As ascertained in a previous study (Jeanneret, 1949), the relationship between the amplitude of unipolar limb lead electrocardiograms and the skin resistance depends on potential losses through the shunts existing in certain circuits.* The resistance of a biological electric current generator is an important factor for all procedures where it has to support a load (Kahlson, 1920; Holzer, 1936), as is the case for the galvanometric method, as well as for the electronic amplifiers when a shunt exists in the patient circuit.

In the present paper we merely intend to describe the method that served us for quick clinical measurements of the body-and-electrode resistance with an ordinary amplifier electrocardiograph. Thus it was also easy to verify clinically a new process for lowering the patient's skin resistance, as described by Bell et al. (1939), and to prove that this process entirely meets the requirements of the unipolar limb leads (Jeanneret, 1949).

Thirty years ago, Einthoven (1916), followed by Burger (1926), measured the body resistance with a string galvanometer. This is shown in Fig. 2. Tracing $\mathrm{K}$ shows the response of the string to the standardizing signal, without a patient in the circuit and tracing $L$ the response with a patient in series. Knowing the string resistance, it is easy to calculate the body resistance. Unfortunately the results of this method may be distorted by the electrical capacity of the skin; furthermore the string instrument is seldom used in the hospitals on the Continent. - For these reasons, it proved necessary to find another clinical method; the laboratory procedures for determining the d.c. resistance and the a.c. impedance of the human body have not been overlooked, but they require special equipment and their accuracy is greater than needed for our purpose (Einthoven et al., 1922; Holzer, 1936; Bell et al., 1939; Schaefer, 1942; Wyss, 1946).

\section{Principle of The Method}

If a source of electromotive force " $e$ " and internal resistance " $r$ " is connected across the terminals of a resistance " $s$ ", then a potential difference given by the expression

$$
v=e \times \frac{s}{s+r}
$$

will be developed between these terminals. The potential drop $(\mathrm{e}-\mathrm{v})$ may be expressed as a percentage of " $e$ " and this value called " $Y$ ". Thus:

$$
\mathrm{Y}=\frac{100(\mathrm{e}-\mathrm{v})}{\mathrm{e}} \text { per cent } . \quad . \quad . \quad . \quad . \quad . \quad . \quad . \quad .
$$

Combining equations (1) and (2):

$$
Y=\frac{100 r}{s+r} \text { per cent }
$$

* For example, in the circuit as described originally by Wilson (1934). 
This expresses as a percentage the drop between the open-circuit voltage " $e$ " and the potential difference " $v$ " at the terminals of a source connected across a resistance. Finally equation (3) gives:

$$
\mathrm{s}=\frac{100 \mathrm{r}}{\mathrm{Y}}-\mathrm{r} \Omega \quad \cdot \quad \cdot \quad \cdot \quad \cdot \quad \cdot \quad \cdot \quad \cdot \quad \cdot \quad \cdot \quad .
$$

It is easy to record with an ordinary high input-impedance amplifier cardiograph the opencircuit voltage (" $e$ ") of a source of known internal resistance and then to record its voltage " $v$ " connected across the human body (" $\mathrm{s}$ "). From the deflection produced by " $\mathrm{e}$ " and " $\mathrm{v}$ ", " $\mathrm{Y}$ " may be readily found (equation 2) and the resistance of the patient's body can be calculated from equation (4).

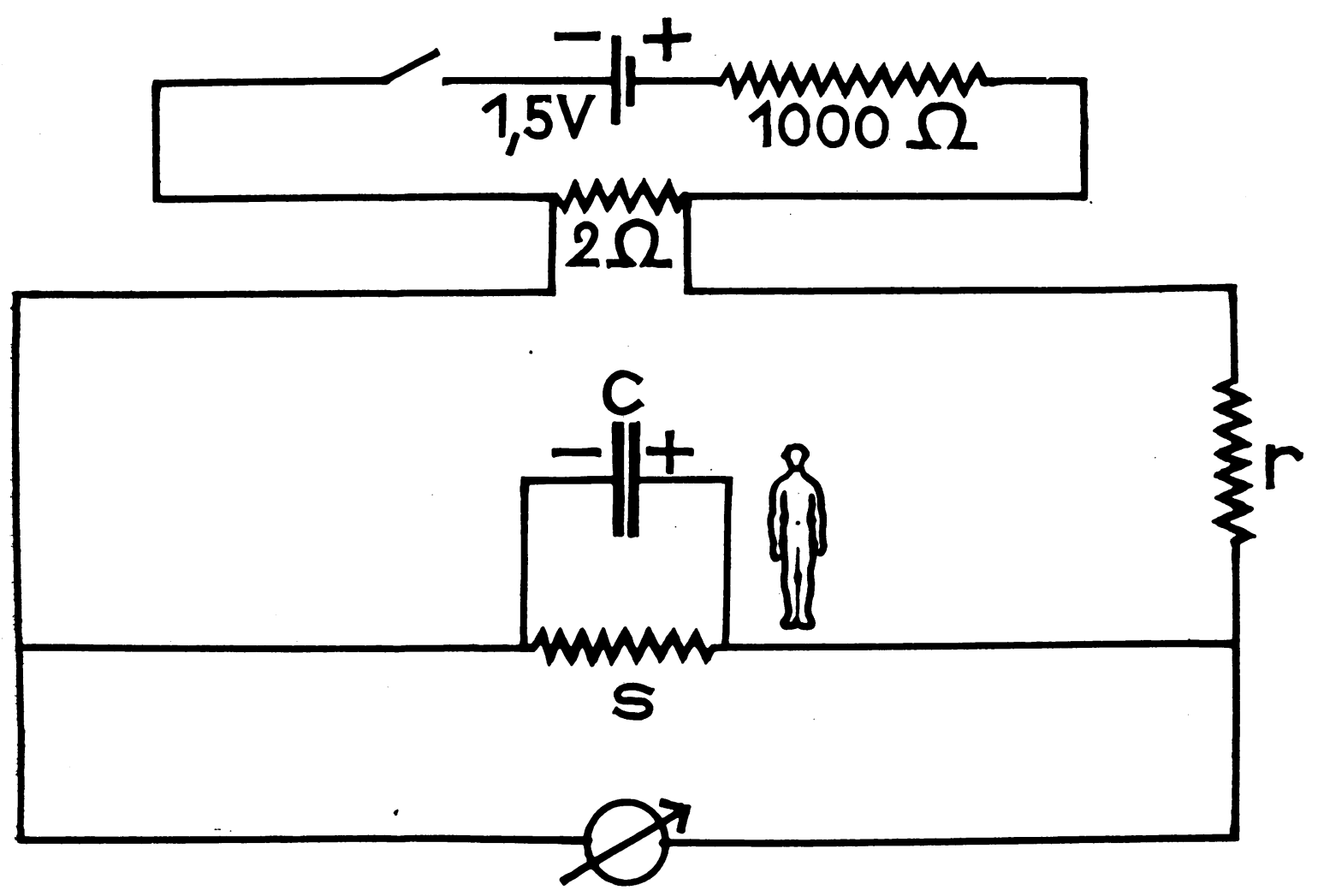

FIG. 1.-Circuit for measuring the body resistance, used in conjunction with an amplifier cardiograph, by connecting a potential difference across the patient. The source of current consists of a voltage divider (top) in series with a dry cell of $1.5 \mathrm{~V}$ providing about $3 \mathrm{mV}$ at the terminals of the $2 \Omega$ resistor. A switch supplies rectangular potential waves. The resistor " $r$ " plays the part of the internal resistance of the source. In order to test the effect of skin capacity the potentials are connected across a resistor in parallel with a condenser (C). Further details in the text.

\section{The ApParatus}

The open-circuit voltage (Fig. 2 A) generated by a voltage divider (Fig. 1) is registered through the total resistance $(r+2 \Omega)$, then it is recorded when shunted across the patient (Fig. 2 B). By measuring from each tracing the deflections thus obtained, the value " $Y$ " is readily calculated (equation 2) and " $s$ " can be found (equation 2).

The resistance $(\mathrm{r}+2 \Omega)$ of Fig. 1 plays the part of the internal resistance of the source and must be introduced in equation (4). As " $r$ " is great with regard to the $2 \Omega$ resistor of the potential divider, " $\mathrm{r}$ " may be substituted for $(\mathrm{r}+2 \Omega)$. 


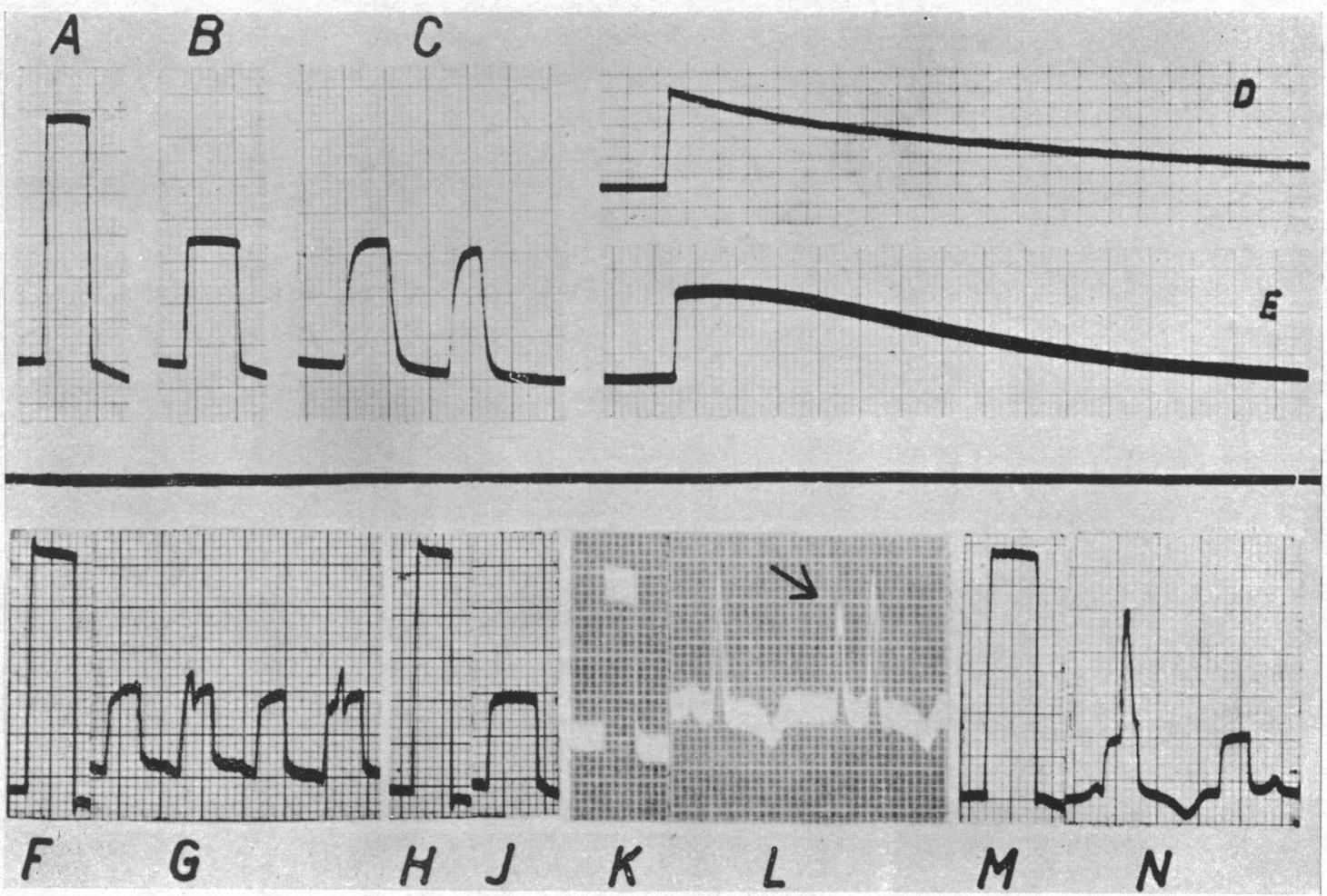

FIG. 2.-Records obtained with the circuit of Fig. 1. The skin of the patients was prepared with the electrode jelly of Jenks and Graybiel (1935).

$A, B, C$. Experiment on a model circuit: (A) record of " $\mathrm{e}$ ". (B) Connection across a resistance " $\mathrm{s}$ " $=5 \times 104 \Omega$ : record of " $\mathrm{v} "$. (C) Same as $B$, but the resistor is paralleled by a condenser of $1 \mu \mathrm{F}$. $A, B, C$ at the same sensitivity setting of the instrument. Resistor " $\mathrm{r} "=5 \times 104 \Omega$.

$D, E$. Decay curves: $(D)$ short time-constant amplifier. $(E)$ Sanborn amplifier.

$F, G$. Subject $P . F .:(F)$ record of "e". (G) Record of " $\mathrm{v}$ ". Resistor "r " $=5000 \Omega$. "Y " $=66 \cdot 1$ per cent. Subject's body resistance, " $s "=2600 \Omega$.

$H, J$. Same subject: the ECG is eliminated as explained in the text. $(H)$ Record of "e ". (J) Record of "v". "Y" $=64 \cdot 2$ per cent; " $s "=2800 \Omega$, coinciding fairly with the previous measurement.

$K, L$ and $M, N$. Subject $M$. D.

$K, L$. Measurement by means of a cambridge string galvanometer. String resistance: $4500 \Omega$. Calculated body resistance: $3100 \Omega$. Further details in the text.

$M, N$. Measurement with the circuit of Fig. 1: "Y $"=77 \cdot 2$ per cent; " $s "=3000 \Omega$. Fair agreement between the two methods, as the low skin resistance (electrode jelly) avoids a capacitive overshooting.

The accuracy of the method is not better than 10 per cent for measuring resistance up to $10^{4} \Omega$ and 15 per cent between $10^{4} \Omega$ and $2 \times 10^{4} \Omega$, corresponding to the unavoidable error of 5 per cent at least when measuring " $Y$ " with a clinical cardiograph (Council on Phys. Med., 1947; Elmqvist, 1939).

\section{EFFECT OF THE ELECTRICAL CAPACITY OF THE SKIN}

A discussion of the conducting properties of the skin or an analysis of the skin impedance is beyond the scope of this paper (Einthoven et al., 1922; Schaefer, 1942; Liechti and Stephan, 1944; Lepeschkin, 1947). Yet to show the part played by the skin capacity, a condenser in parallel with a resistor may be put as a load on the source of current, in place of the ohmic resistance only. When rectangular potentials are applied to this capacity-resistance system, it is obvious (Fig. $2 \mathrm{C}$ ) that the time of rise of the voltage pulse to the maximum value tends to be prolonged by a time interval 
corresponding to the loading of the condenser; the top-level of the wave is, however, the same as the level reached when the connection is made across a resistance only (Fig. 2 B). The method here described can accordingly be used to measure a patient's resistance without errors arising from the skin capacity. This is valid provided that the time constant of the resistance-capacity coupled amplifier used is long enough for the top of the voltage waves, delayed by the capacitive shunt, to be reached before the decay of the tracing. The Sanborn instrument used meets this requirement because of the slow initial rate of decay of its standardization curve (Fig. $2 \mathrm{E}$ ) which shows no drop before 0.3 sec., owing to its special compensation circuit (Miller, 1938). An amplifier with too short a time constant (Fig. 2 D), would not be convenient for this purpose (the maximum delay due to skin capacity was found to be $0.12 \mathrm{sec}$.).

\section{ELIMINATION OF THE SUPERIMPOSED ELECTROCARDIOGRAM}

When the voltage of the potential divider is applied to the human body, the electrocardiogram is superimposed upon the small rectangular potential waves and the measurement of their magnitude may become difficult (Fig. $2 \mathrm{~N}$ ). This trouble can be avoided by using a higher voltage and reducing the sensitivity of the amplifier. Unfortunately the commercial cardiographs lose their accuracy at low sensitivity, when too large a voltage overloads their input stage. This condition is easily overcome with a voltage divider, properly shielded, made up of high value resistors (Sanborn, 1949), in order not to modify the input characteristics of the instrument. (With a potential divider of $1 \mathrm{megohm}$ and $5 \times 10^{4} \Omega$ in series, $60 \mathrm{mV}$ are reduced to $2.8 \mathrm{mV} ; 60 \mathrm{mV}$ are supplied by $1000 \Omega$ in series with $40 \Omega$ instead of $2 \Omega$, in the circuit as shown in Fig. 1.) Fig. $2 \mathrm{G}$ shows the shape of the voltage waves connected across the body, distorted by the electrocardiogram superimposed on the tracing. Fig. $2 \mathrm{H}$ and $\mathrm{J}$, show the tracings produced by the procedure modified as mentioned above, and it may be seen that the electrocardiogram does not appear on the records of the voltage connected across the body (Fig. $2 \mathrm{~J}$ ).

\section{SUMMARY}

A simple circuit was devised for measuring clinically, with an amplifier type of electrocardiograph, the electrical d.c. resistance of a patient. This procedure is based on the shunt of a known voltage through the body and no error arises from the skin capacity. Calculations are quick and the method is easily practised with few accessories to the cardiograph. Brief preliminary mention is made of the part played by the patient's resistance in special electrocardiographic procedures, even in conjunction with an electronic amplifier.

\section{REFERENCES}

Bell, G. H., Knox, J. A. C., and Small, A. J. (1939). Brit. Heart J., 1, 3.

Burger, R. (1926). Z. klin. Med., 102, 603.

Council on Physical Medicine (1947). Minimum Requirements for Acceptable Electrocardiographs. J. Amer. med. Asss., 134, 455.

Einthoven, W., Bergansius, F. L., and Bijtel, J. (1916). Pflüg. Arch. ges. Physiol., 164, 167.

Einthoven, and Bijtel, J. (1922). Ibid., 197, 439.

Elmqvist, R. (1939). Verh. dtsch. Ges. Kreisl. Forsch., 12, 7.

Holzer, W. (1936). Z. Kreisl Forsch., 28, 113.

Jeanneret, P. (1949). Helvet. Medica. Reta, 16, 548.

Jenks, L., and Graybiel, A. (1935). Amer. Heart J., 10, 693.

Kahlson, G. (1920). Pflüg. Arch. ges. Physiol., 220, 132.

Lepeschkin, E. (1947). Das Elektrokardiogramm. Dresden u. Leipzig (Steinkopff).

Liechti, A., and Stephan, E. (1944). Arch. Kreisl. Forsch., 13, 289.

Miller, A. (1938) Engineering Aspects of Electrocardiography. Thesis, Massachussets Inst. of Techn., El. Eng. Dept., Cambridge, Mass., U.S.A.

Sanborn Company (1949). Personal communication.

Schaefer, H. (1942). Spezielle Elektrophysiologie. Wien (Deuticke).

Wilson, F. N., Johnston, F. D., Macleod, A. G., and Barker, P. S. (1934). Amer. Heart J., 9, 447.

Wyss, O. (1946). Helvet. physiol. Acta, 4, C6.

This investigation was under the direction of Dr. A. Delachaux. 